\title{
Structural Analysis of the Casings in Deep Geothermal Wells
}

\author{
Gunnar Skúlason Kaldal1,2, Magnús P. Jónsson ${ }^{1}$, Halldór Pálsson ${ }^{1}$, Sigrún Nanna Karlsdóttir ${ }^{1}$ \\ 1Faculty of Industrial Engineering, Mechanical Engineering and Computer Science, University of \\ Iceland, Hjarðarhagi 2-6, 107 Reykjavík, Iceland \\ 2ÍSOR - Iceland GeoSurvey, Grensásvegi 9, 108 Reykjavík, Iceland
}

\begin{abstract}
With recent increasing interest in drilling deep geothermal wells in order to produce from higher enthalpy heat sources than before, the strength of the casing becomes one of the most limiting factors. Casing failures include collapse or partial collapse (bulges) and tensile ruptures if wells are allowed to cool down or are killed by pumping water into them. Structural impact of large temperature and pressure changes remains one of the challenges to be solved for utilization of deep geothermal wells. Thermal expansion of materials, degradation of structural properties at elevated temperatures, corrosion and cyclic loads are of particular concern as well as determining how many thermal cycles casings can go through before failure occurs. A nonlinear structural finite-element model of the cased section of high temperature geothermal well is presented and discussed here. The purpose of the model is to evaluate the structural integrity of casings when subjected to large temperature and pressure loads. The model can be used further to evaluate well designs and material selections for deep geothermal wells.
\end{abstract}

Keywords: Casings, structural analysis, finite-element method, thermal loads, deep drilling

*email: gsk@isor.is

\section{Introduction}

This paper provides an overview of structural modeling of casings in high temperature geothermal wells. Structural integrity of high temperature geothermal wells is important for utilization and safety concerns on the surface. During each drilling phase, steel casings are run in hole and cemented externally, until the last phase where the production section of the well is drilled. This is done to control wells during drilling, seal off unwanted feed-zones and the last casing, the production casing, acts as a pipe allowing the geothermal fluid (water and/or steam) to flow to the surface. In most cases, a perforated liner is placed in the production section to avoid formation collapse. Above the liner is the cased section of the well, which is a layered structure of multiple cemented casings. The structure is initially relatively cold, i.e. during drilling and cementing, compared to the hot conditions during production of

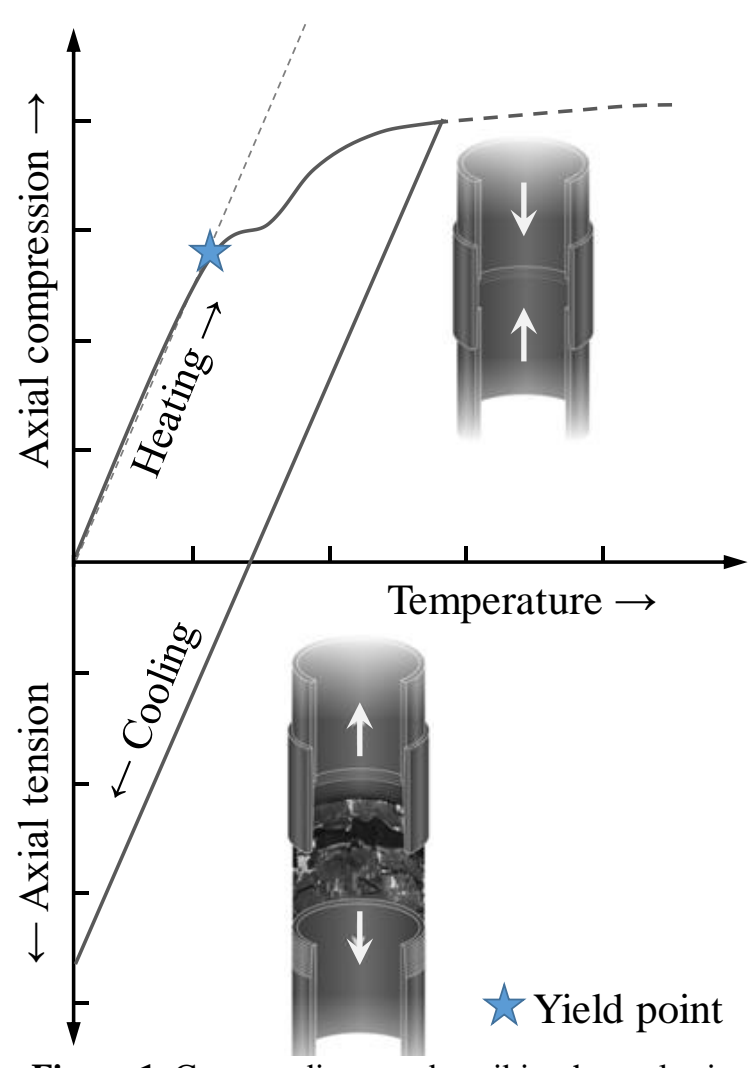

Figure 1. Concept diagram describing how plastic strain that forms in axial compression can result in axial tension during cooling. Adopted from a diagram by (Rahman \& Chilingarian, 1995). 
(two-phase or pure) steam. As cement sets and hardens after cementing jobs for each casing, its temperature distribution down the well provides initial conditions for subsequent thermal stresses that form as the well warms up. In high-temperature geothermal wells $\left(\mathrm{T}>200^{\circ} \mathrm{C}\right.$ at $1000 \mathrm{~m}$ depth) stresses which generate due to thermal expansion driven by the temperature change between an initially cold well to a producing well, typically reach beyond the yield point of the commonly used casing material, API (American Petroleum Institute) grade K55. As stresses go past the yield strength, plastic permanent strains are produced in the casings. Depending on the magnitude of these plastic strains, some wells, specially the hotter ones, cannot be cooled down again without causing casing failure. In such cases, plastic strains that build up in axial compression (hot well) lead to axial tensile load when the casing cools down again. Figure 1 illustrates this phenomenon, where plastic strains created in compression lead to high tensile stresses when the casing cools down again. Casing failure of tensile rupture of the casing normally occurs in the casing near couplings (first thread groove) or in the threads themselves. In casing design, guidelines acknowledge that axial tension leads to reduced collapse resistance of casings. However, as standards are developed for the oil \& gas industry where casings are anchored at the casing shoe with cement and not cemented over their full length as in geothermal wells, failures as a result axial compressive loads are assumed to be on the form of Euler buckling (or helical buckling) where the casing string buckles laterally. Casings in geothermal wells have no means to displace laterally due to the cement support, instead high compressive stresses and strains are formed which can as with tension reduce their collapse resistance.

The Finite-Element Method (FEM) models shown in this paper have been created to evaluate stresses and strains in casings due to pressure and temperature changes in wells.

\section{Load history of casings}

Casings are cold-drawn seamless steel pipes. Thickness tolerance of such pipes is $12.5 \%$ (API, 2005), meaning that for a 9 $5 / 8$ " $47 \mathrm{lb} / \mathrm{ft}$ casing that is specified with thickness of $12 \mathrm{~mm}$, it may be $12 \mathrm{~mm}$ on one side and $10.5 \mathrm{~mm}$ on the other. Heat treatments are used to relieve residual stresses present in the material due to nonuniform cooling during manufacturing. Residual stresses and non-circular geometry (ovality, eccentricity and wall thickness irregularity) can significantly lower the collapse resistance of casings. Material properties, i.e. yield strength and shape of the stress-strain curve, and residual stresses also affect collapse resistance (ISO/TR, 2007).

While casings are run-in-hole, the highest axial tensile stress occurs at the topmost coupling, which essentially holds up the whole casing string before it is cemented. Buoyancy and friction between the casing, centralizers and the wellbore lower the axial force on top.

Thermal stresses form in casings as wells warm up, which magnitudes are controlled by the temperature difference $\Delta \mathrm{T}$ at each location as well as the (time dependent) thermal gradient through the layered casing structure. The initial conditions are different between wells, and depend on formation temperature, feed zones that are closed off with cement, cooling from drilling and the time the well has been cooled. In many cases, depending on feed zones, drilling time, etc., wells heat up faster downhole as the formation temperature increases with depth. In cases where the cement sets at such temperature conditions, the highest $\Delta \mathrm{T}$ (from cementing conditions to production) is uppermost in the well. This does however not mean that the highest compressive stresses form at the wellhead. At the surface there is freedom for displacement, both because of the design of the wellhead, if it includes an expansion spool, and due to less 
restricted displacement as the surface can displace upwards. Wellheads are known to move upwards as wells warm-up, sometimes called wellhead growth. This is in some cases very evident during discharge initiation, where the temperature uppermost in the well changes quickly, whereas deeper in the well lower $\Delta \mathrm{T}$ is seen. When drilling has been problematic and the wellbore has been cooled for a long period, $\Delta \mathrm{T}$ can be similar at the wellhead and deeper in the well, as the cement sets before the well heats up. The positive side of higher setting temperatures is that less stresses form during production. The down side is that if cement sets at too high temperature, cooling due to further drilling can de-bond the casing from the cement as it contracts, creating a micro-annulus.

As discussed in the introduction, compressive stresses form in the casing as the well warms up and plastic strains form in the most common material used, API grade K55. Using the next higher grade L80 postpones the problem and plastic strains will occur as well. Using the specified minimum yield strength of K55 and L80, $379 \mathrm{MPa}$ and $552 \mathrm{MPa}$ (API, 2005), onset of plastic strains is at around $150^{\circ} \mathrm{C}$ and $200^{\circ} \mathrm{C}$, for $\mathrm{K} 55$ and $\mathrm{L} 80$, respectively (using a thermal expansion coefficient of $13 \mu \mathrm{m} /\left(\mathrm{m}^{\circ} \mathrm{C}\right)$ and Young's modulus of 205 $\mathrm{GPa})$. This however does not tell the whole story as stress-strain characteristics can influence collapse resistance. For a work hardening material such as K55 it has been shown that the API collapse equation applies only for small axial tensile stresses and that the measured collapse resistance is significantly higher than those predicted by the API equation (Maruyama, et al., 1990). They show that due to the work hardening characteristics of grade K55 casing, it may be superior to higher-grade casing for thermal well service where high residual axial tensile stresses may be present.

\section{Field study and FEM analysis}

In this study, wellhead displacement monitoring during discharge initiation is used to validate a FEM model of the cased section of a high-temperature geothermal well (Kaldal, et al., 2015). Figure 2 shows temperature and elevation measurement locations on the wellhead of well HE-46, located in Sleggjubeinsdalur near Hellisheiði power plant.

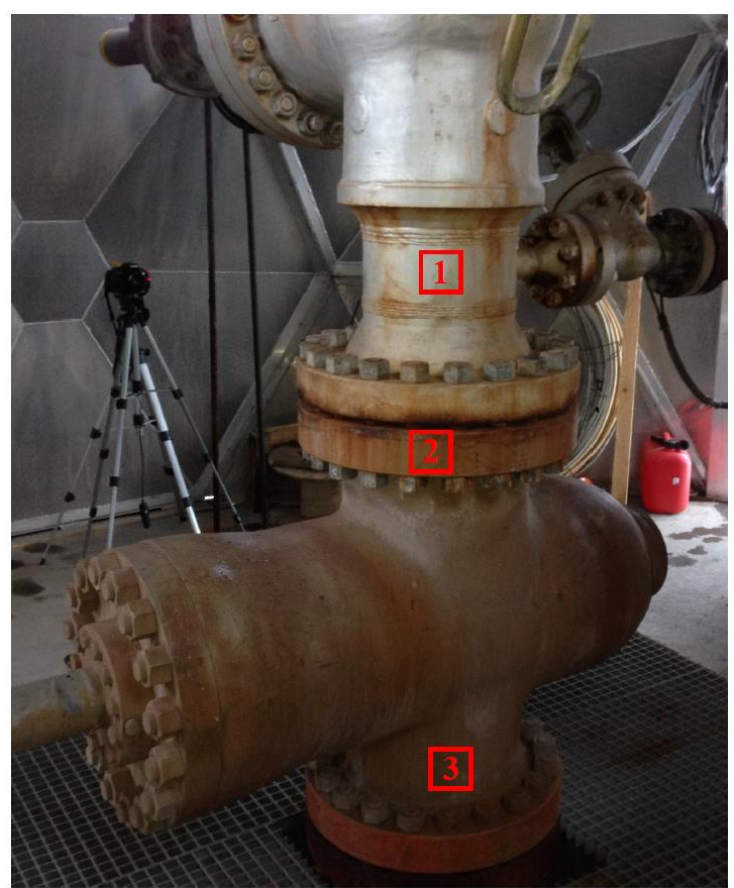

Figure 2. Locations for temperature measurements during discharge initiation of well HE-46, located in Sleggjubeinsdalur near Hellisheiði power plant. Location [2] shows where elevation measurements were taken for the wellhead.

The ANSYS Parametric Design Language (APDL) is used to construct the models. Included are temperature dependent material properties, including stress-strain curves for casing materials, for determining formation of plastic strain, and thermal expansion coefficients. Other material properties include; Young's modulus, Poisson's ratio, density, thermal conductivity, specific heat and compressive strength of cement. Kinematic hardening material model is used for the casings and the compressive strength of cement is included by using a bi-linear material model.

Boundary conditions of the model are at the rock formation outer boundary and bottom where displacements are constrained. Initial conditions of the rock formation is the 
estimated formation temperature and cementing temperature distribution for all casings, which need to be defined for each specific case. Transient thermal analyses include load steps such as cooling due to drilling, thermal recovery where wells heatup over a period of weeks to months, discharge initiation, discharge and well shut-in. Initial conditions for the structural modeling are the formation overburden pressure and residual axial load in casings from casing run-in. Transient thermal results are then used as temperature load in the structural analysis, where displacements, stresses and strains (elastic and permanent plastic strain) are analyzed.

\section{Results}

\section{Wellhead displacement}

Wellhead measurements, i.e. temperature, pressure and elevation changes during discharge initiation were taken for several wells including the case studied here, well HE-46.

Temperature changes, shown in Figure 3, are similar for two separate discharges, conducted in years 2011 and 2013. Wellhead pressure, measured for the 2011 discharge, is initially 37.5 bar-g and after discharge initiation (at 13:16 o'clock on graph), it lowers and stabilizes at 18 bar-g. In 2013 the wellhead pressure was initially 48 bar and after discharge initiation it stabilized at 16 bar-g.

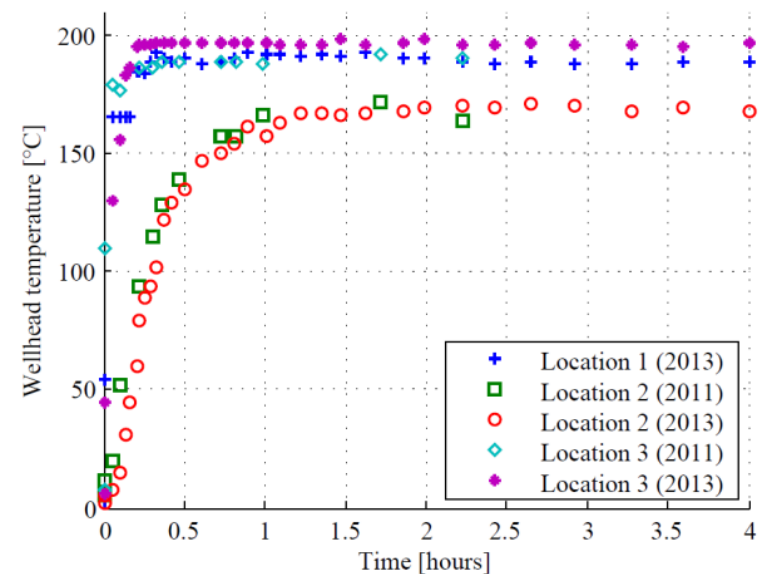

Figure 3. Temperature during discharge initiation of well HE-46, measurement locations are shown in Figure 2 (Kaldal, et al., 2012) (Kaldal, et al., 2015).

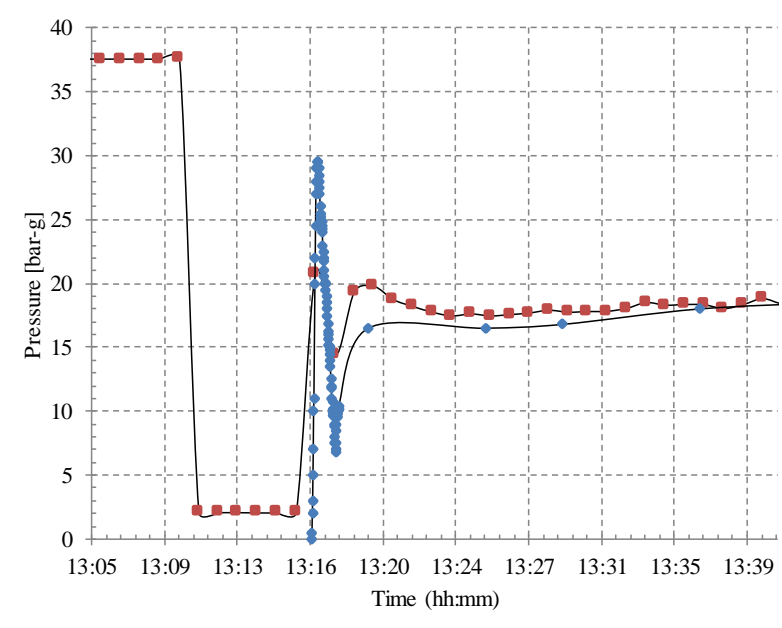

Figure 4. Wellhead pressure changes during discharge initiation (well opened at time 13:16). Campbell data (taken at $1 \mathrm{~min}$ intervals) shows initial pressure of 37.5 bar-g. Note that lowering in pressure in Campell data before discharge is due to closing of control valve and both pressure gauges are behind it (Kaldal, et al., 2012) (Kaldal, et al., 2015).

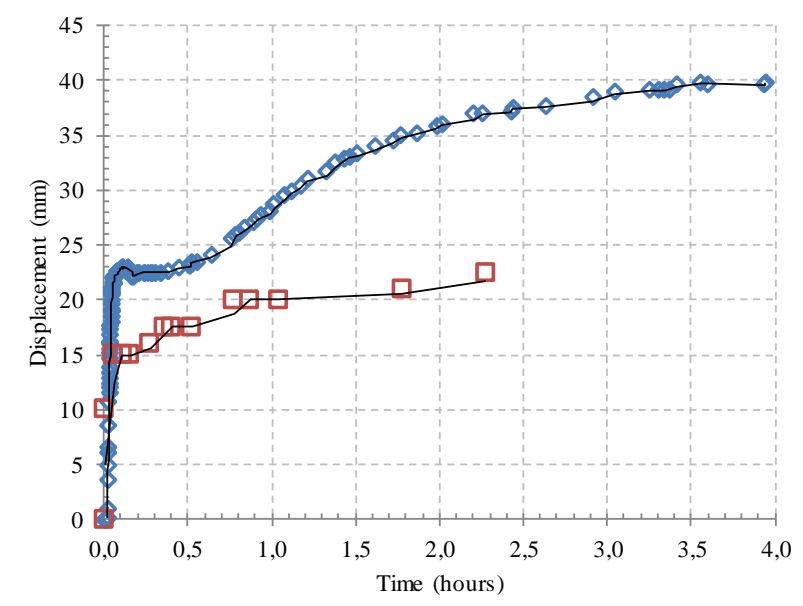

$\diamond$ HE-46 (2013) $\square$ HE-46 (2011)

Figure 5. Measured displacement of the wellhead of two separate discharges of well HE-46 in years 2011 and 2013 (Kaldal, et al., 2012) (Kaldal, et al., 2015).

Measured wellhead displacements for the two separate discharges, shown in Figure 5, differ by $15 \mathrm{~mm}$ after $2 \mathrm{~h}$ of discharge. In 2013, wellhead displacement measured 37 $\mathrm{mm}$ and in 2011, it was $22 \mathrm{~mm}$, in both cases after $2 \mathrm{~h}$ of discharge. 


\section{FEM results}

During installation while casings are run in hole, wells are kept full of water or mud and the casing is filled with water. Depending on the situation, a buoyancy force and friction counteracts the casing's self weight. The largest tensile forces should occur at the top of the casing that hangs in the well. A buttress-threaded connection (BTC) is modeled. Assuming no buoyancy or friction, i.e. casing hanging in air, stresses forms in the threads of the connections as is shown in Figure 6.

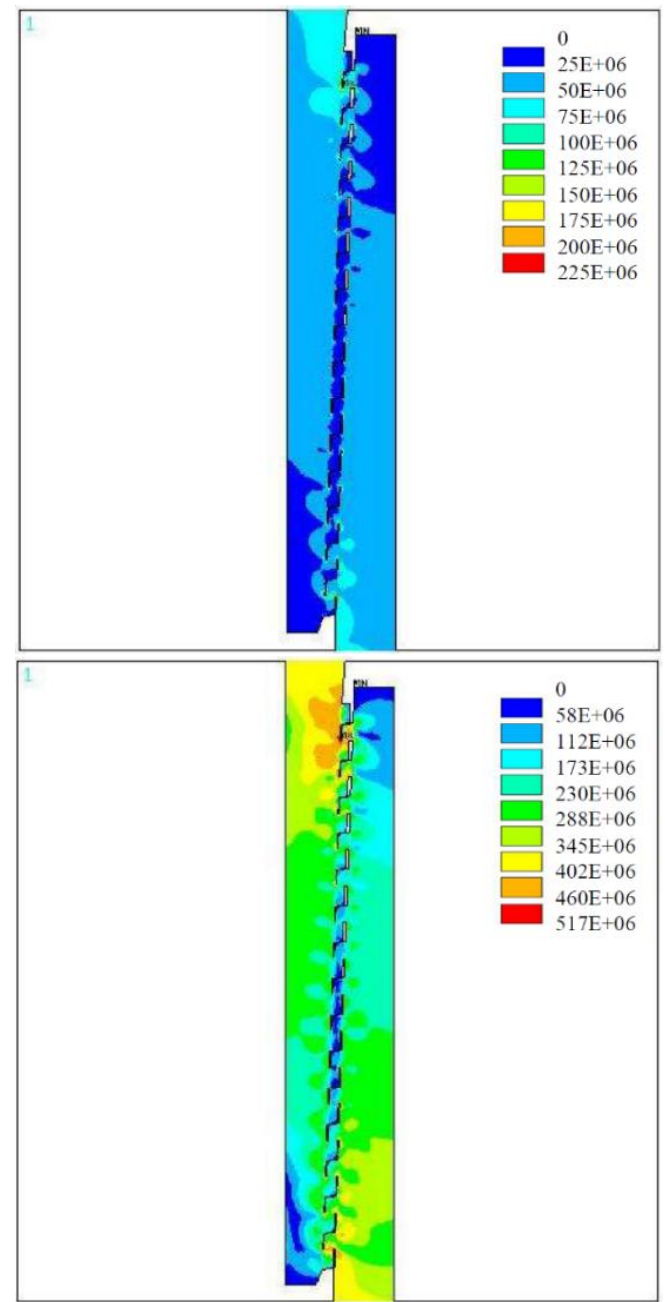

Figure 6. Von Mises stress $(\mathrm{Pa})$ of buttress threaded connection (BTC) during installation assuming 700 $\mathrm{m}$ (top) and $5000 \mathrm{~m}$ (bottom) casing hanging from the connection in free in air. For API K55 grade casings the minimum yield strength is $379 \mathrm{MPa}$ (API, 2005).

Two cases are taken, conventional $700 \mathrm{~m}$ casing and extreme $5000 \mathrm{~m}$ casing. assuming $95 / 8 " 47 \mathrm{lb} / \mathrm{ft}$ casing. In the former, the stresses are below yield of any API casing grade, but for the latter, stresses above yield occur in the area of the casing where the first threads are located. This implies a risk zone of casing failure due to axial tension.

After drilling, and warm-up, wells are flow tested. A simulation of flow test of well HE-46 results in wellhead displacement of $30 \mathrm{~mm}$ after 2 hours of discharge, whereas the measured value was at $36 \mathrm{~mm}$ (Figure 7). The modeled wellhead displacement, shown in Figure 8, shows that the production casing slides slightly inside the wellhead due to thermal expansion.

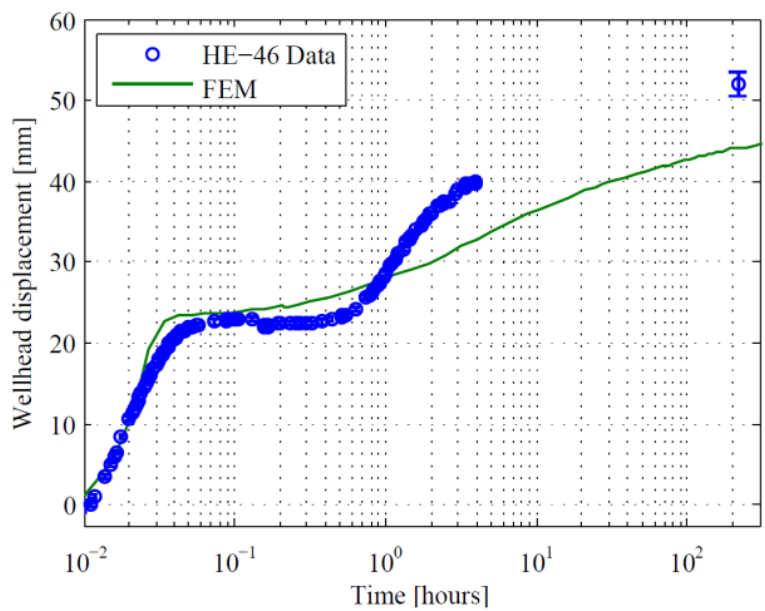

Figure 7. Measured displacement during discharge (2013 data) and modeled displacement in green (Kaldal, et al., 2015).

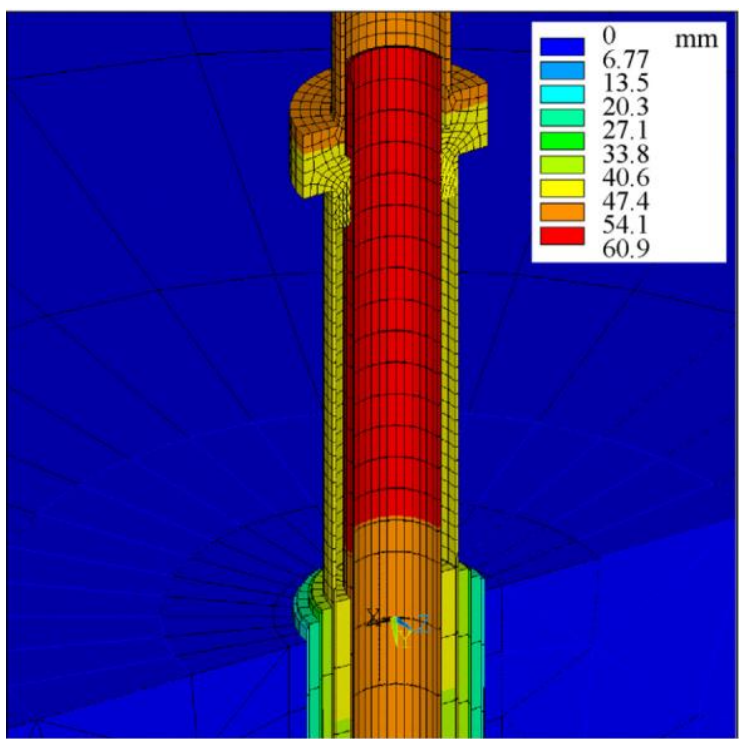

Figure 8. Modeled wellhead displacement due to thermal expansion of casings, also shown in Figure 7 (Kaldal, et al., 2015). 


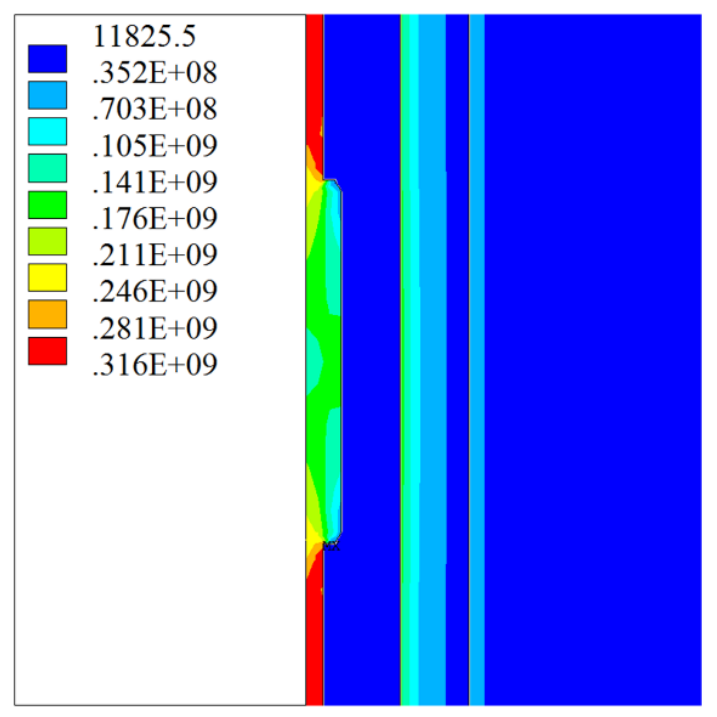

Figure 9. Modeling of casings during discharge shows high compressive stresses forming near couplings, which anchor the casing in the cement (Kaldal, et al., 2015).

Deeper in the well, where the casings are more constrained than at the surface, discharge initiation results in compressive stresses forming due to thermal expansion as the well heats up. Figure 9 shows compressive stresses in the production casing near a simplified connection, illustrating how the casing is anchored at the couplings in the cement. In this case, the treads are not modeled and therefore lower stresses are seen in the coupling.

Modeling shows high stresses forming in the cement at these anchoring locations as the production expands. Figure 10 shows modeling of stresses near the uppermost coupling of the production casing as it displaces upwards. Stresses above the compressive strength $(27 \mathrm{MPa})$ of the cement occurs at the top of the coupling. After the compressive strength is reached, the cement deforms according to its defined bi-linear material curve, explaining higher stresses.

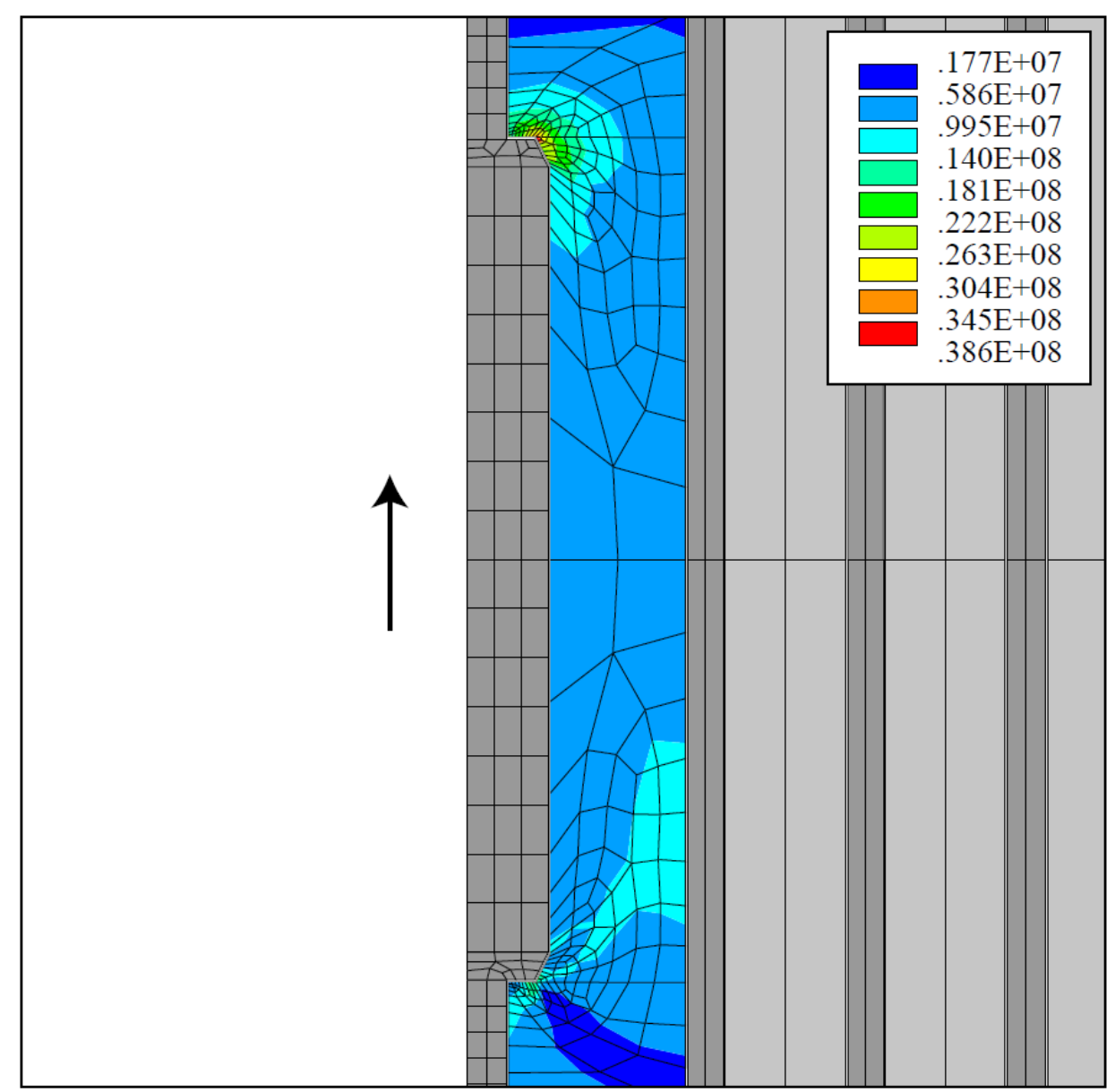

Figure 10. As wells heat up, high stresses develop in cement near the couplings that anchor the thermally expanding production casing in the cement (casings and simplified coupling shown in dark gray and external concrete shown in gray). 
Modeling of casing collapse due to annular pressure, i.e. due to expansion of water in cement/annulus during discharge, shows that cement support has vital effect on the casing's collapse form (Figure 11). Casings without cement support collapse completely, but with the support the collapse is less severe. A small defect is included on the external surface of the casing for introducing instability to the model to allow buckling. Figure 12 shows that the collapse resistance of the uncemented casing is much less than that of the cemented casing.

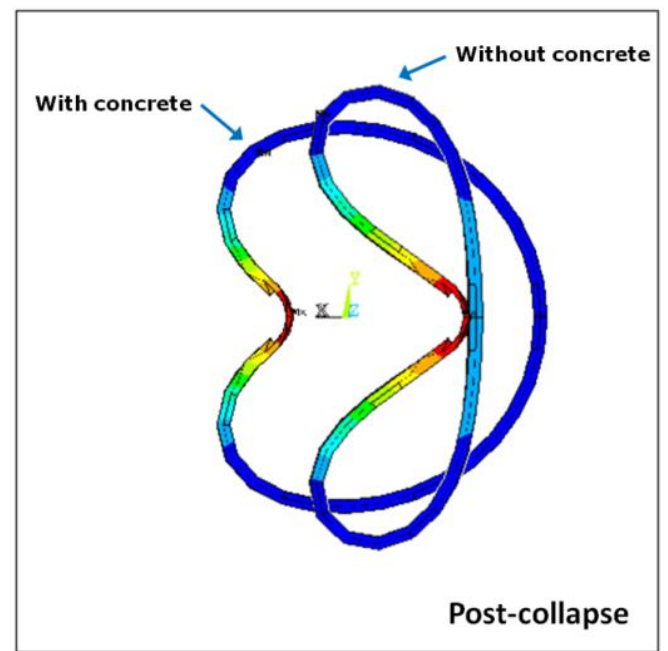

Figure 11. Collapse form of casing with and without external cement structural support (Kaldal, et al., 2013).

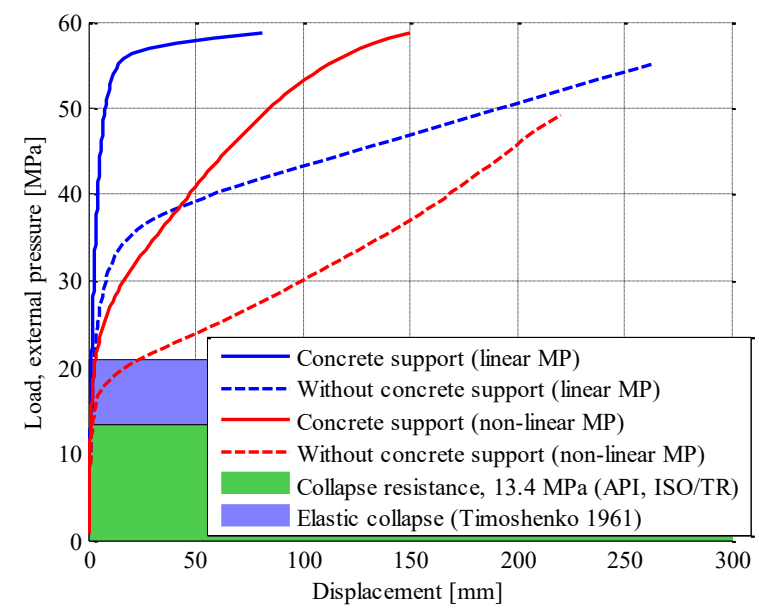

Figure 12. Modeled collapse of casings shows increased collapse resistance with cement structural support (Kaldal, et al., 2013).

\section{Discussion}

Measurements of wellhead displacement during discharge initiation was used to validate results from a FEM model of the cased section of a high-temperature geothermal well. Although temperature monitoring of well HE-46 showed similar values, two separate discharges (two years apart) show different outcome in wellhead displacement. The cause of this unclear, but many factors could influence the displacement, e.g. $\mathrm{T}$ and $\mathrm{P}$ wellbore conditions can be different although wellhead conditions are similar, constraints of the wellhead might be different as two years are between measurements, the wellhead might be less constrained in the latter case due to cement cracking near the top.

In FEM analysis of threaded casing/coupling connection, the highest stresses occur in the area of the casing where the first threads are located. Casing failures of tensile ruptures have been seen at this location in wells that were quenched by pumping cold water into them. In another case, in well IDDP-1 in Iceland, where premium connections were used, the threads of the casing were swept off due to high shear force in the threads.

The models show that the casings are anchored at the couplings that stand out into the cement. Therefore, higher stresses are seen in the cement nearby couplings.

According to the FEM results, collapse resistance of casings increases when cement is present in the annulus, and the collapse form is less severe than for non-cemented casings, that completely collapse together.

\section{Conclusions}

Nonlinear FEM structural modeling of casings in high-temperature geothermal wells was presented. As most wells experience temperature change that leads to thermal stresses above the yield strength of casing materials commonly used, API grades K55, L80 and T95, plasticity needs to be considered. This is addressed by 
defining nonlinear material stress-strain curves, and using multilinear kinematic hardening material model. Modeling such as this requires knowledge about the structure, its initial conditions and loads in the form of temperature and pressure changes. Load history is therefore important, to fully understand the structure's response to loads. For drilling deeper wells to challenging pressures and temperatures and assuring a lasting well, the structural design needs to be carefully considered to include all aspects of the design. Including material challenges of strength reduction at elevated temperatures, thermal expansion, corrosion and embrittlement, wellhead pressure class. Modeling such as shown here provides an excellent tool for evaluating stresses and strains for future well designs.

\section{Acknowledgement}

This PhD work was financially supported by the University of Iceland research fund, the Technology Development Fund at RANNIS - The Icelandic Centre for Research, the Innovation Center Iceland, Landsvirkjun Energy Research Fund, and GEORG - Geothermal Research Group. Their support is greatly appreciated. The authors would like to thank Reykjavik Energy, HS Orka, Landsvirkjun, Iceland Drilling, ÍSOR - Iceland GeoSurvey, Mannvit and the Innovation Center Iceland for providing data and useful discussion and information for the work presented here.

\section{References}

API, 2005. API Standard 5CT (ISO 11960:2004) Specification for Casing and Tubing. 8th ed. Washington: American Petroleum Institute.

ISO/TR, 2007. ISO/TR 10400, Petroleum and natural gas industries - equations and calculations for the properties of casing, tubing, drill pipe and line pipe used as casing or tubing. Geneva: ISO copyright office.

Kaldal, G. S., Jonsson, M. T., Palsson, H. \& Karlsdottir, S. N., 2012. Thermal and Structural Analysis of the Casings in a High Temperature Geothermal Well During Discharge. s.l., Thirty-Seventh Workshop on Geothermal Reservoir Engineering, Stanford University, Stanford, California, January 30 - February 1, 2012.

Kaldal, G. S., Jonsson, M. T., Palsson, H. \& Karlsdottir, S. N., 2013. Collapse analysis of the casing in high temperature geothermal wells. Stanford, California, s.n.

Kaldal, G. S., Jonsson, M. T., Palsson, H. \& Karlsdottir, S. N., 2015. Structural Analysis of Casings in High Temperature Geothermal Wells in Iceland. Melbourne, Australia, World Geothermal Congress 2015.

Kaldal, G. S., Jonsson, M. T., Palsson, H. \& Karlsdottir, S. N., 2015. Structural modeling of the casings in high temperature geothermal wells. Geothermics, Volume 55, pp. 126-137.

Kaldal, G. S., Jonsson, M. T., Palsson, H. \& Karlsdottir, S. N., 2016. Structural modeling of the casings in the IDDP-1 well: Load history analysis. Geothermics, pp. 111.

Maruyama, K. et al., 1990. An Experimental Study of Casing Performance Under Thermal Cycling Conditions. SPE, pp. 156-164.

Rahman, S. S. \& Chilingarian, G. V., 1995. Casing design theory and practice. Amsterdam - Lausanne - New York Oxford - Shannon - Tokyo: Elsevier. 